Perfor mance of the new y instal I ed vertical neut $r$ on camer as for I ow neut $r$ on yi el d di scharges in the Large Hel i cal Devi ce

\begin{tabular}{|l|l|}
\hline $\begin{array}{l}\text { jour nal or } \\
\text { publ i cat } \mathrm{i} \text { on } \mathrm{t} \text { i t l e }\end{array}$ & Revi ew of Sci ent i f i c I nst rument s \\
\hline vol une & 91 \\
\hline number & 8 \\
\hline page $\mathrm{r}$ ange & 083505 \\
\hline year & $2020-08$ 07 \\
\hline URL & ht t p: //hdl . handl e. net /10655/00012768 \\
\hline
\end{tabular}




\title{
Performance of the newly installed vertical neutron cameras for low neutron yield discharges in the Large Helical Device
}

\author{
S. Sangaroon, , ,a) K. Ogawa,,$^{1,2, b)}$ M. Isobe, ${ }^{1,2, c)}$ M. I. Kobayashi, ${ }^{1,2, d)}$ Y. Fujiwara, ${ }^{1, e)}$ S. Kamio, ${ }^{1, f)}$ R. \\ Seki, ${ }^{1,2, g)}$ H. Nuga, ${ }^{1, h)}$ H. Yamaguchi, ${ }^{1, i)}$ M. Osakabe ${ }^{1,2, j)}$ and LHD Experiment Group ${ }^{1}$ \\ ${ }^{I}$ National Institute for Fusion Science, National Institutes of Natural Sciences, Toki 509-5292, Japan \\ ${ }^{2}$ The Graduate University for Advanced Studies, SOKENDAI, Toki 509-5292, Japan
}

(Presented XXXXX; received XXXXX; accepted XXXXX; published online XXXXX)

(Dates appearing here are provided by the Editorial Office)

Two new vertical neutron cameras characterized by high detection efficiency were developed on the Large Helical Device in order to observe poloidal structures of helically-trapped beam ions created by the perpendicularly injected positive-ion based neutral beam (P-NB) and are newly operated since 2018. In this work, the neutron fields at the vertical neutron cameras are investigated using Monte Carlo N-Particle transport code to evaluate the performance of its collimators. The results indicate that neutrons are attenuated by the heavy concrete and are well collimated through the collimator to detectors. Neutron spectra at the detector position show over $99 \%$ of uncollided $2.45 \mathrm{MeV}$ neutrons. Time evolution of neutron emission profiles during the short pulse of P-NB injection is measured by the vertical neutron cameras. Peaks on the neutron emission profiles corresponding to the helically-trapped beam ion are successfully obtained, as designed. The decrease of line integrated neutron flux at the peak positions after the P-NB stops is consistent with the behavior of total neutron emission rate measured by the neutron flux monitor.

\section{INTRODUCTION}

Understanding of energetic particle transport and loss due to energetic-particle-driven magnetohydrodynamic (MHD) mode is one of the key issues in order to obtain better plasma performance in fusion devices. ${ }^{1}$ The energetic particle transport behaviors were successfully demonstrated in tokamaks using the neutron camera. A neutron camera based on parallel collimators was installed in the basement of the Tokamak Fusion Test Reactor (TFTR). ${ }^{2,3}$ The timeresolved and the spatially-resolved neutron emission profiles during high frequency MHD activity were obtained in TFTR. ${ }^{3}$ The horizontal and vertical neutron cameras were installed at the Joint European Torus (JET). ${ }^{4,5}$ The

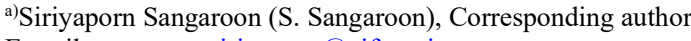

E-mail sangaroon.siriyaporn@nifs.ac.jp.

${ }^{\text {b) Kunihiro Ogawa (K. Ogawa) }}$

E-mailkogawa@nifs.ac.jp.

${ }^{c}$ Mitsutaka Isobe (M. Isobe)

E-mail isobe@nifs.ac.jp.

d)Makoto I. Kobayashi (M. I. Kobayashi)

E-mail kobayashi.makoto@nifs.ac.jp.

${ }^{\text {e)} Y u t a k a \text { Fujiwara (Y. Fujiwara) }}$

E-mail fujiwara.yutaka@nifs.ac.jp.

${ }^{f)}$ Shuji Kamio (S. Kamio)

E-mailkamio@nifs.ac.jp.

${ }^{g}$ Ryosuke Seki (R. Seki)

E-mail seki.ryohsuke@nifs.ac.jp.

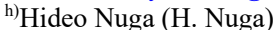

E-mail nuga.hideo@nifs.ac.jp.

${ }^{i)}$ Hiroyuki Yamaguchi (H. Yamaguchi)

E-mail yamaguchi.hiroyuki@nifs.ac.jp.

${ }^{j}$ Masaki Osakabe (M. Osakabe)

E-mailosa@nifs.ac.jp.
}

instruments allow to study the evolution of neutron emissivity poloidal distribution using tomographic reconstruction method. ${ }^{6}$ The vertically inclined multichannel collimator was installed at the JAERI Tokamak 60 Upgrade (JT-60U). ${ }^{7,8}$ The energetic ion transport during the neutral beam heating is observed with the neutron camera at JT-60U. ${ }^{9}$ The horizontal and vertical neutron cameras based on JET neutron camera is planned to be installed at ITER. ${ }^{10,11}$ The understanding of energetic particle physics obtained by the neutron camera will provide essential information for the achievement of burning plasma in ITER.

In stellarators and helical devices, in particular, the behavior of helically-trapped beam ion which is created by the perpendicularly neutral beam injections is crucial in the core plasma physics regarding the loss of the energetic ion or the limiting of the ion temperature because of a lack of symmetry of the system. The loss of helically trapped beam proton perpendicularly injected by a diagnostic neutral beam injector was investigated in the Compact Helical System (CHS) with a conventional neutral particle analyzer (NPA) ${ }^{12}$ During the hydrogen plasma experiment of Large Helical Device (LHD), the fast ions confinements during the ion cyclotron resonance heating and neutral beam heating were experimentally investigated ${ }^{13}$ using a comprehensive set of fast ion diagnostics. ${ }^{14}$ In particular, confinement property of the helically trapped proton accelerated by ion cyclotron resonance heating has been studied in the LHD using the natural diamond detectors as a solid-state NPA. ${ }^{15}$ In order to sustain the high-temperature state, the study of helically-trapped beam ion behavior is important and will 
provide the crucial information for the deep understanding of energetic ions confinement property. Unlike the combination of a hydrogen discharge and NPA, in deuterium discharges, the information related to the energetic ions behavior in plasma core can be directly obtained from neutrons which are mainly produced from the reaction between beam ions and bulk ions. The LHD equipped with three tangentially injected negative-ionsource-based neutral beam injections and two perpendicularly injected positive-ion-source-based neutral beam injections (P-NBs) can provide heating power up to 35 MW. The deuterium plasma experiments have been operated at LHD since March 2017. The expected maximum total neutron emission rate $\left(S_{\mathrm{n}}\right)$ is $1.9 \times 10^{16} \mathrm{n} / \mathrm{s} .{ }^{16}$ The comprehensive neutron diagnostics are developed and working at LHD in order to enhance the understanding of the energetic-particle physics in the LHD. ${ }^{17-19}$ To study the energetic particle transport through the time-resolved and the spatially-resolved measurement, the neutron cameras have been developed and used in LHD. The first vertical neutron camera (the so-called $\mathrm{VNC} 1$ ) was developed for working at $S_{\mathrm{n}}$ of $1.9 \times 10^{16} \mathrm{n} / \mathrm{s}^{20,21} \mathrm{VNC} 1$ has been providing the crucial information in order to study the energetic ion confinement property in LHD. ${ }^{17,18,22,23}$ However, in the plasma discharge with strong MHD activities, $S_{\mathrm{n}}$ is approximately two orders of magnitude lower $\left(S_{\mathrm{n}} \sim 3 \times 10^{14} \mathrm{n} / \mathrm{s}\right)$ than the expected maximum $S_{\mathrm{n}}{ }^{23}$ To achieve higher time-resolved neutron emission profile measurements during MHD activities, new vertical neutron cameras (the so-called VNC2 and the so-called VNC3) characterized by high detection efficiency were developed and are operated since 2018. This paper is devoted to discussing the performance of $\mathrm{VNC} 2$ and $\mathrm{VNC} 3$ using numerical simulation and shows experimental results.

\section{NEW VERTICAL NEUTRON CAMERAS}

The VNC2 has nine sight lines each having an inner diameter of $5 \mathrm{~cm}$. Sight lines align radially at radius $(R)$ of $3.339 \mathrm{~m}, 3.420 \mathrm{~m}, 3.501 \mathrm{~m}, 3.644 \mathrm{~m}, 3.725 \mathrm{~m}, 3.806 \mathrm{~m}$, $3.949 \mathrm{~m}, 4.021 \mathrm{~m}$, and $4.093 \mathrm{~m}$. The VNC3 has eight sight lines each having an inner diameter of $5 \mathrm{~cm}$. Sight lines align radially at $R$ of $3.4 \mathrm{~m}, 3.5 \mathrm{~m}, 3.6 \mathrm{~m}, 3.7 \mathrm{~m}, 3.8 \mathrm{~m}, 3.9$ $\mathrm{m}, 4.0 \mathrm{~m}$, and $4.1 \mathrm{~m}$. The $\mathrm{VNC} 2$ and $\mathrm{VNC} 3$ are installed parallel at LHD lower port (so-called $1.5 \mathrm{~L}$ port) to view different plasma cross-sections in order to observe the poloidal structure of helically-trapped beam ions created by the P-NBs. ${ }^{24}$ Figure 1(a) shows the location of the P-NB\#4, $\mathrm{P}-\mathrm{NB} \# 5$, and two helical ripples $\mathrm{A}$ and $\mathrm{B}$ between the two helical coils. Fig. 1(b) shows the horizontally elongated poloidal cross section where the P-NB is injected at the helical ripple A. As shown in Fig. 1(a), both P-NBs mainly create helically-trapped beam ions in the helical ripple A. The typical density profile of beam ion created by P-NBs calculated using the guiding center orbit following model MORH code ${ }^{25}$ together with the VNCs sight line are shown in Fig. 2. The relatively high-density region of helicallytrapped beam ion appears in the upper region of poloidal cross sections at VNC2 and VNC3 positions which
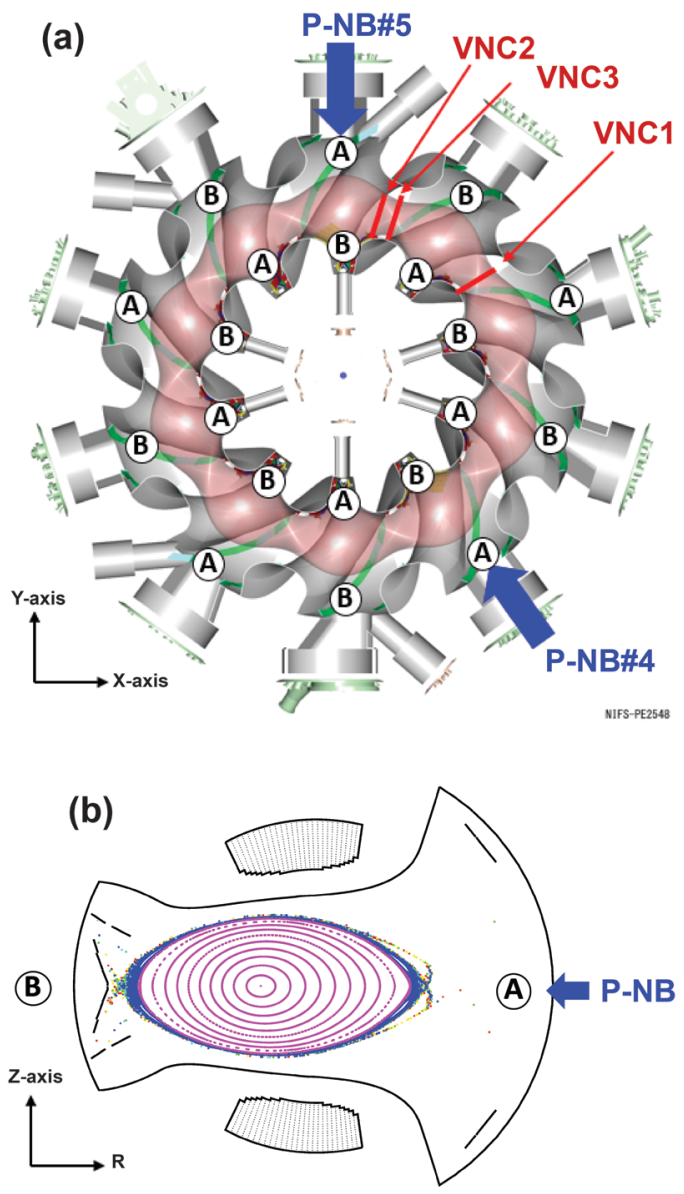

FIG. 1. (a) A schematic view of LHD and the position of P-NBs heating injections, $\mathrm{A}$ and $\mathrm{B}$ are the outer and inner helical ripple regions between the coil. The location of $\mathrm{VNC} 2$ and $\mathrm{VNC} 3$ are also shown. (b) A horizontally elongated poloidal cross section together with helical winding coil where the P-NB is injected.
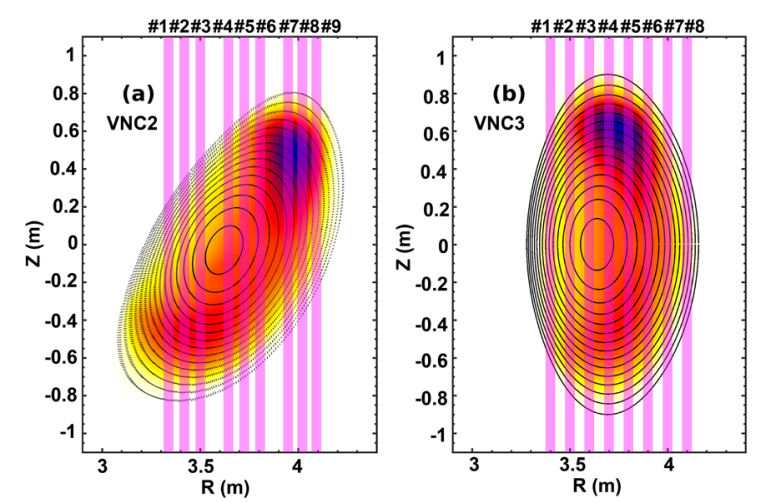

FIG. 2. Typical density profile of beam ions created by the P-NBs (a) where the VNC2 is installed and (b) where the VNC3 is installed. Vertical pink bars indicate sight lines of VNCs.

correspond to the helical ripple A. The detectors used in the neutron camera are model EJ-410 ${ }^{26}$ and are based on silver activated zinc sulfide phosphor ( $\mathrm{ZnS}: \mathrm{Ag}$ ) embedded in hydrogenous polymer matrix structured in a series of concentric cylinders with diameter of $5.08 \mathrm{~cm}$ and thickness 


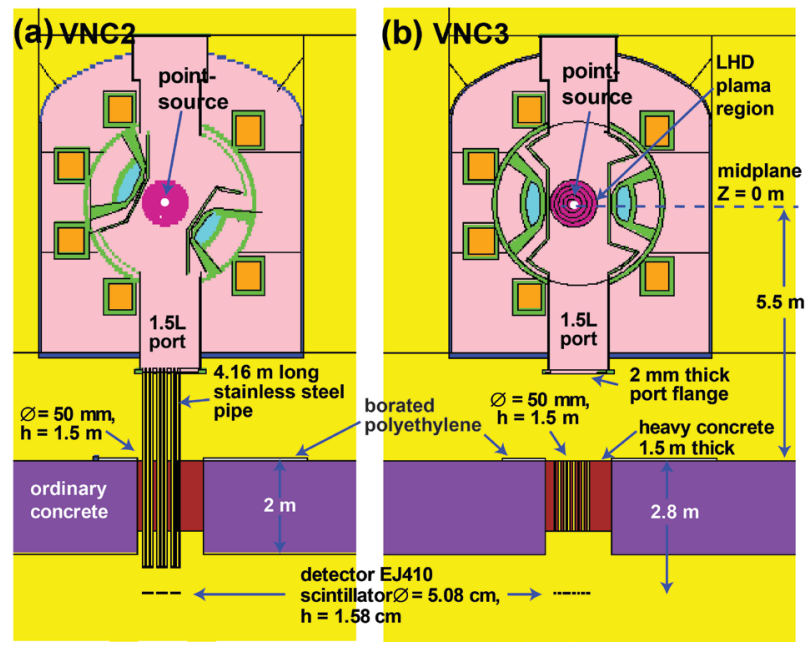

FIG. 3. MCNP calculation models of (a) VNC2 calculation and (b) VNC3 calculations.

of $1.58 \mathrm{~cm}$. EJ-410 has high fast neutron detection efficiency $\left(E_{\mathrm{n}}>1 \mathrm{MeV}\right)$ and is insensitive to gamma ray. The EJ-410 scintillator is directly coupled with the two-inch size photomultiplier (H7195, Hamamatsu Photonics K.K.). ${ }^{27}$ The anode signal is fed into the low-impedance current amplifier (C7319, Hamamatsu Photonics K.K.). ${ }^{28}$ The detectors are operated with current mode to record the neutron emissivity profile with higher temporal resolution (up to $200 \mathrm{kHz}$ ). The detectors are equipped to the fast digitizer acquisition system with the sampling frequency of $1 \mathrm{MHz}$ (PXI6133, National Instruments). ${ }^{29}$

\section{NEUTRONICS CALCULATION}

\section{A. Modeling for MCNP calculation}

The neutron fields at VNC2 and VNC3 are investigated using the Monte Carlo N-Particle transport code MCNP6 ${ }^{30}$ and the cross-section library of FENDL-3.0. ${ }^{31}$ The LHD and torus hall were modeled based on the simplified CAD drawing. ${ }^{32-35}$ In this calculation, parallel vertical sight lines of stainless steel (SUS304) pipes with $5 \mathrm{~cm}$ inner diameter and $0.1 \mathrm{~cm}$ thick embedded in the $1.5 \mathrm{~m}$ thick hematite $\left(\mathrm{Fe}_{2} \mathrm{O}_{3}\right)$-doped heavy concrete and installed in the $2 \mathrm{~m}$ thick torus floor ordinary concrete are modeled as collimators at $1.5 \mathrm{~L}$ port of LHD for VNC2 and VNC3 as shown in Fig. 3(a) and 3(b), respectively. The hematite heavy concrete used for $\mathrm{VNC} 2$ and $\mathrm{VNC} 3$ are the same as that used for $\mathrm{VNC}^{21}$ which provides low level of unwanted gamma-rays compared to collimator made of polyethylene. An array of stainless steel (SUS304) pipes with inner diameter of $3.8 \mathrm{~cm}$, length of $416 \mathrm{~cm}$ and thickness of $0.15 \mathrm{~cm}$ which is used for neutral particle analyzer based on single crystal CVD diamond detector ${ }^{36}$ is modeled along the VNC2. The $2 \mathrm{~mm}$ thick port flange is modeled for VNC3. To study the collimator performance and spatial resolution of the VNCs, a point neutron source with the energy of $2.45 \mathrm{MeV}$ is used and located on the torus midplane $(Z=0 \mathrm{~m})$ at collimator central axis of primary channel of $\mathrm{VNC} 2$ and $\mathrm{VNC} 3$
TABLE I. Definition of primary and secondary channel number for VNC2 and VNC3.

\begin{tabular}{|c|c|c|}
\hline \hline & primary channel no. & secondary channel no. \\
\hline VNC2 & $\# 5(R=3.725 \mathrm{~m})$ & $\begin{array}{l}\# 4(R=3.644 \mathrm{~m}) \\
\# 6(R=3.806 \mathrm{~m})\end{array}$ \\
\hline \multirow{2}{*}{ VNC3 } & $\# 4(R=3.7 \mathrm{~m})$ & $\# 3(R=3.6 \mathrm{~m})$ \\
& & $\# 5(R=3.8 \mathrm{~m})$ \\
\hline \hline
\end{tabular}

calculations (see channel number in Table I). The neutron field has been calculated by using track length estimation tally (the so-called cell tally in MCNP6) with volume of $32.18 \mathrm{~cm}^{3}$ which is located at $Z=8.3 \mathrm{~m}$ below the midplane. Note that the neutron flux in this work is presented in relative value.

\section{B. Calculation results of a point neutron source}

\section{Neutron distribution}

Figure 4(a) and 4(b) show the image plots of neutron flux distribution in energy range of $0.1-2.45 \mathrm{MeV}$ at VNC2 and at VNC3 cross section, respectively. It is clearly seen that neutrons are attenuated by the heavy concrete and are well collimated through the primary collimators to the detectors. It is clearly seen in Fig. 4(b) that neutron is observed by the neighboring channels which is referred to as a neutron crosstalk. Here, we define the neutron crosstalk by the ratio of the average neutron flux measured at secondary channel to that measured at primary channel (see channel number in Table I).

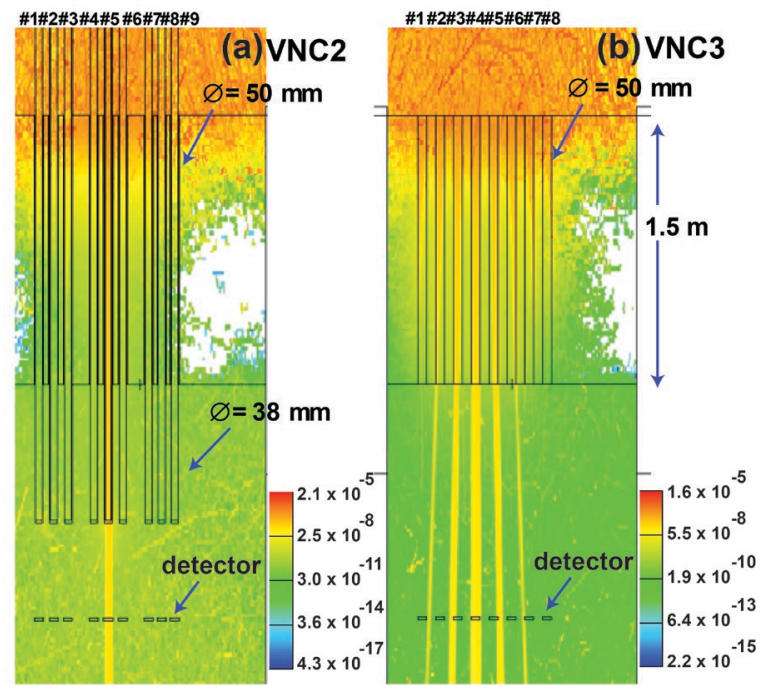

FIG. 4. Neutron flux distribution at the collimator and detector position of (a) VNC2 and (b) VNC3. 


\section{The VNC performance}

Figure 5 shows the neutron spectra at the detector of primary channels of $\mathrm{VNC} 2$ and $\mathrm{VNC} 3$ in energy range of 0.1-2.45 MeV. There are clear peaks of virgin neutron at energy of $2.45 \mathrm{MeV}$ whereas the contribution of scattered neutron is continuous. The results show that virgin neutron at detector of $\mathrm{VNC} 2$ is about $54 \%$ lower than virgin neutron at detector of VNC3 due to smaller collimator diameter. The spectra show that neutron fluxes at the detector are dominated by over $99 \%$ of virgin $2.45 \mathrm{MeV}$ neutrons. The spatial profiles of $\mathrm{VNC} 2$ and $\mathrm{VNC} 3$ are conducted as shown in Fig. 6(a) and 6(b). The scattered neutrons are approximately constant and approximately three orders of magnitude lower than the virgin $2.45 \mathrm{MeV}$ neutrons on the primary channels. The neutron flux at the inner radius channel $(R=3.339 \mathrm{~m}$ of VNC2 and $R=3.4 \mathrm{~m}$ of VNC3 $)$ is about one order of magnitude higher than the neutron flux at the next channel due to the thin layer of heavy concrete in the inner radius side (see Fig. 3). Most of the neutron flux at the inner radius channel of $\mathrm{VNC} 2$ is dominated by scattered neutron due to the collision in stainless steel pipes while at the inner radius channel of VNC3 is dominated by virgin neutron streaming through the collimator.

The spatial resolutions have been estimated from the Gaussian fit of $2.45 \mathrm{MeV}$ neutron. It is found to be $\sim 6 \mathrm{~cm}$ and $\sim 13 \mathrm{~cm}$ in FWHM (Full Width at Half Maximum) for VNC2 and VNC3, respectively. The spatial resolution of VNC3 is about $5 \mathrm{~cm}$ wider than the spatial resolution which has been evaluated for $\mathrm{VNC}^{32}$ due to the broad distance between two sight lines and the larger collimator diameter. Further, about $0.3 \%$ of neutron crosstalk is observed in VNC2 while about $16 \%$ is observed in VNC3 (see Table II). The obtained neutron crosstalk on VNC3 is high which may cause the relatively high overestimation on the measured neutron flux. Therefore, the performance improvement toward the lower neutron crosstalk on VNC3 is determined. Discussion for reducing the neutron crosstalk is described in section $\mathrm{V}$.

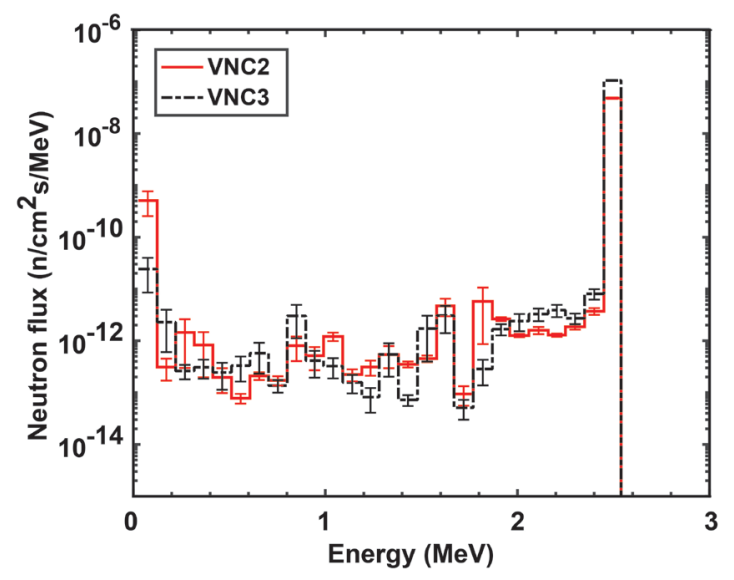

FIG. 5. Neutron energy spectra at the primary channel's detector of $\mathrm{VNC} 2$ and $\mathrm{VNC} 3$.
TABLE II. Neutron crosstalk, where $\Phi$ is total neutron flux.

\begin{tabular}{|c|c|c|c|}
\hline \hline & $\Phi_{\text {primary }}$ & $\begin{array}{c}\text { Average } \\
\Phi_{\text {secondary }}\end{array}$ & Crosstalk \\
\hline $\mathrm{VNC} 2$ & $4.8188 \times 10^{-8}$ & $1.6305 \times 10^{-10}$ & 0.0034 \\
\hline $\mathrm{VNC} 3$ & $1.0583 \times 10^{-7}$ & $1.7050 \times 10^{-8}$ & 0.1611 \\
\hline \hline
\end{tabular}
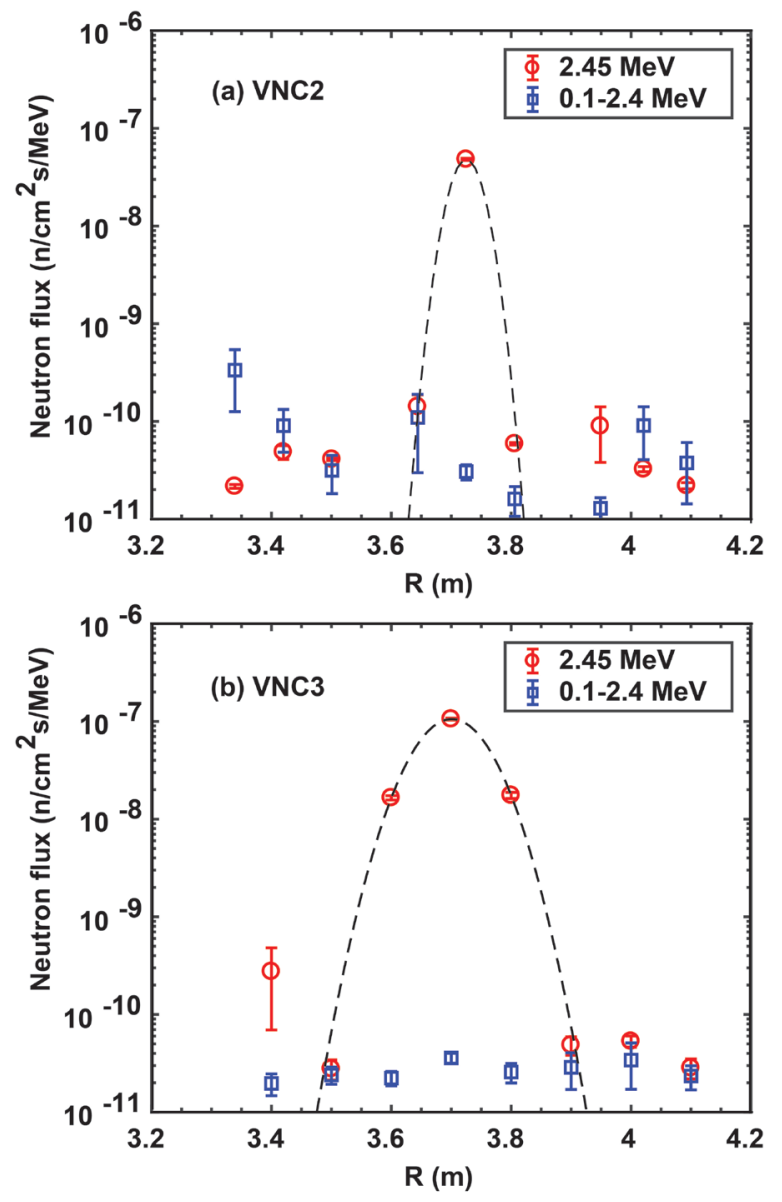

FIG. 6. Neutron flux profiles of 2.45 MeV neutron and 0.1-2.4 MeV neutron at detector positions calculated for (a) VNC2 and (b) VNC3.

\section{MEASUREMENT OF NEUTRON EMISSION PROFILE IN A P-NB HEATED PLASMA}

Time-resolved measurement of neutron emission profile was performed in the deuterium plasma experiment (Fig. 7). In this experiment, the magnetic axis position at vacuum $R_{\text {ax_vac }}$ is set to be $3.6 \mathrm{~m}$, toroidal magnetic field strength is set to be $2.75 \mathrm{~T}$ with clockwise (CW) direction from the top view, line average electron density $n_{\text {e_avg }}$ of about $1.5 \times 10^{19} \mathrm{~m}^{-3}$, and central electron temperature $T_{\mathrm{e} 0}$ of about $6 \mathrm{keV}$. The short pulses ( $40 \mathrm{~ms}) \mathrm{P}-\mathrm{NB} \# 4$, with an injection power of $\sim 7 \mathrm{MW}$, have been injected into the $\mathrm{ECH}$ plasma, with an ECH injection power of $\sim 3 \mathrm{MW}$. Due to the short pulses P-NB, the $S_{\mathrm{n}}$ measured by the neutron flux monitor increases during the short pulse P-NB injection and decays after the P-NB stops. The line-integrated neutron 


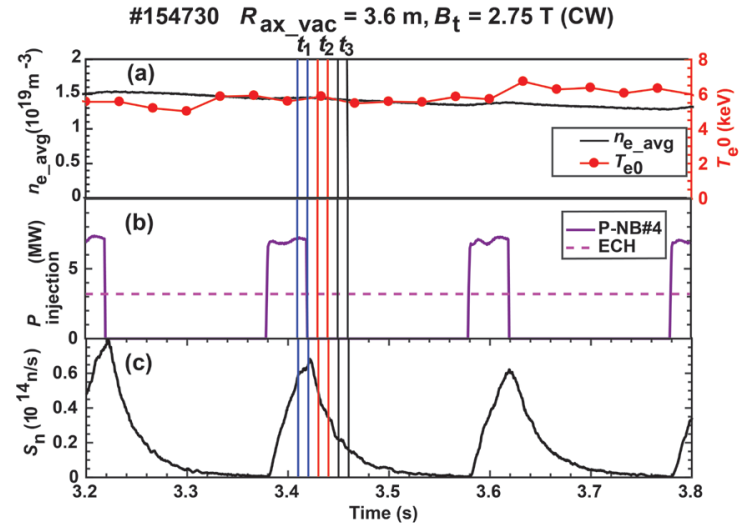

FIG. 7. Time evolution of deuterium plasma shot \#154730 performed at LHD. (a) line-averaged electron density $n_{\mathrm{e}}$ avg and central electron temperature $T_{\mathrm{e} 0}$. (b) the short pulses P-NB\#4 and $\mathrm{ECH}$ are injected during selected time. (c) $S_{\mathrm{n}}$ measured by LHD neutron flux monitor. Three-time slices, $t_{1}: 3.41 \mathrm{~s}$ to $3.42 \mathrm{~s}, t_{2}: 3.43$ $\mathrm{s}$ to $3.44 \mathrm{~s}$ and $t_{3}: 3.45 \mathrm{~s}$ to $3.46 \mathrm{~s}$, are selected to determine the neutron emission profile.
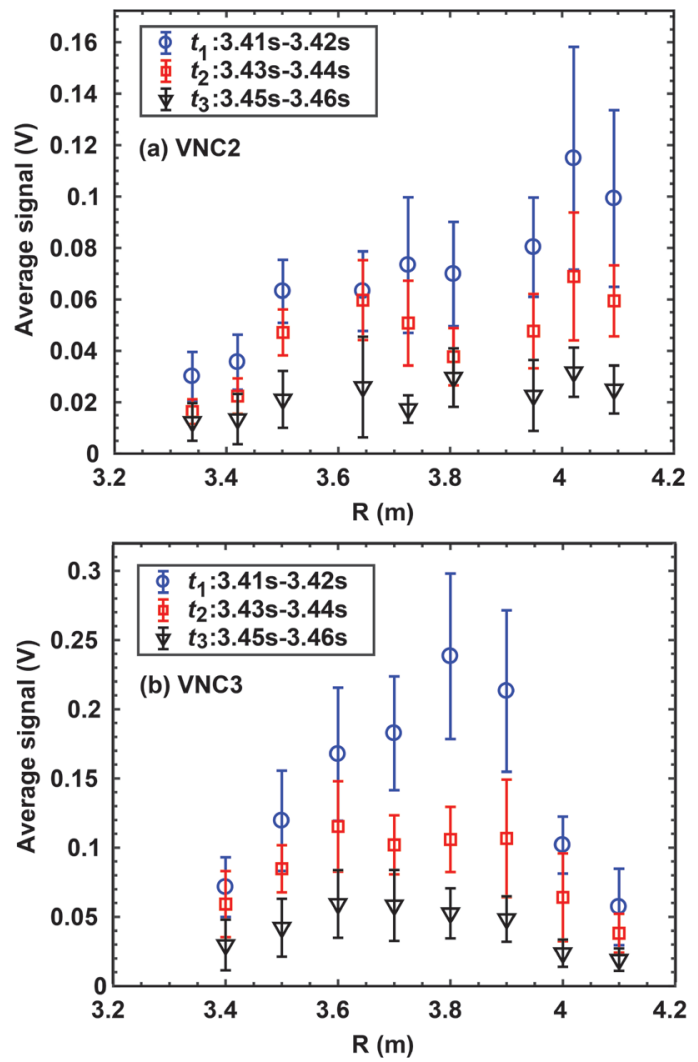

FIG. 8. The line-integrated neutron emission profile measured by (a) the $\mathrm{VNC} 2$ and (b) the $\mathrm{VNC} 3$.

emission profiles of averaged voltage in a function of $R$ at $t_{1}: 3.41 \mathrm{~s}$ to $3.42 \mathrm{~s}, t_{2}: 3.43 \mathrm{~s}$ to $3.44 \mathrm{~s}$, and $t_{3}: 3.45 \mathrm{~s}$ to 3.46 $\mathrm{s}$ are analyzed and presented in Fig. 8(a) and 8(b). Line integrated neutron emission profiles measured by VNC2 has peak at $R \sim 4.0 \mathrm{~m}$, whereas that measured by VNC3 has a peak at $R \sim 3.8 \mathrm{~m}$. Peaks of the obtained neutron emission profile are consistent with the location of helical ripple valley, as shown in Fig. 2. Moreover, it is clearly seen that the decrease of line integrated neutron flux at the peak positions after the beam stops is consistent with the $S_{\mathrm{n}}$ presented in Fig. 7(c). The results show that the neutron emission profile corresponding to poloidal structure of helically-trapped beam ion made by P-NB injection are successfully obtained.

\section{VNC3 PERFORMANCE IMPROVEMENT TOWARD LOWER CROSSTALK}

To reduce the neutron crosstalk, two conceptual designs, pre-collimator and leading pipe, have been introduced in the calculation model for VNC3. The precollimator is made of stainless steel (SS316L) with $5 \mathrm{~cm}$ diameter cylinder hole on the same vertical axis of $\mathrm{VNC} 3$ and is placed above 1.5L port flange (Fig. 9(a)). An array of stainless steel (SUS304) pipes with inner diameter of 4.56 $\mathrm{cm}$ and thickness of $0.15 \mathrm{~cm}$ are inserted vertically from $1.5 \mathrm{~L}$ port along the VNC3 (Fig. 9(b)) as the leading pipe model. In this calculation, the pre-collimator thickness is varied between $5 \mathrm{~cm}$ and $30 \mathrm{~cm}$ whereas the length of the leading pipe is varied between $50 \mathrm{~cm}$ and $465.2 \mathrm{~cm}$ (distance from $1.5 \mathrm{~L}$ port to detector).

The neutron crosstalk is evaluated, and in addition, the spatial resolution is obtained. For the pre-collimator model (see Fig. 10(a)), the neutron crosstalk decreases exponentially, while the pre-collimator thickness increases. The number of total neutrons and virgin $2.45 \mathrm{MeV}$ neutrons are almost the same which means the pre-collimator does not induce the scattered neutrons. Further, the narrow FWHM is observed. The $15 \mathrm{~cm}$ thickness of the precollimator, with the weight of approximately 0.7 tons, provides less than $1 \%$ of the neutron crosstalk and spatial resolution of $\sim 6 \mathrm{~cm}$ in FWHM. It is found that at minimum FWHM of $\sim 6 \mathrm{~cm}$ is limited by the distance between collimators. The obtained results show that pre-collimator can adjust to change the viewing cone of the sight line, resulting in the reduction of the neutron crosstalk and

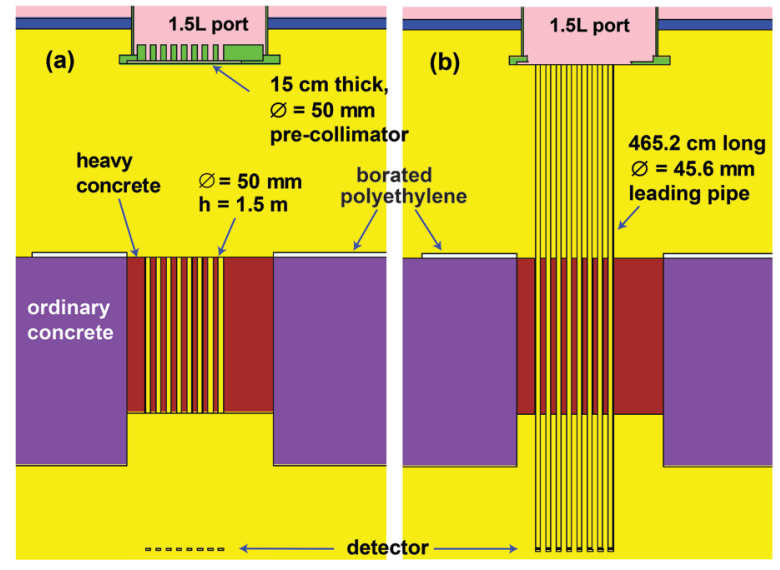

FIG. 9. MCNP calculation model of VNC3 (a) pre-collimator and (b) leading pipe. 

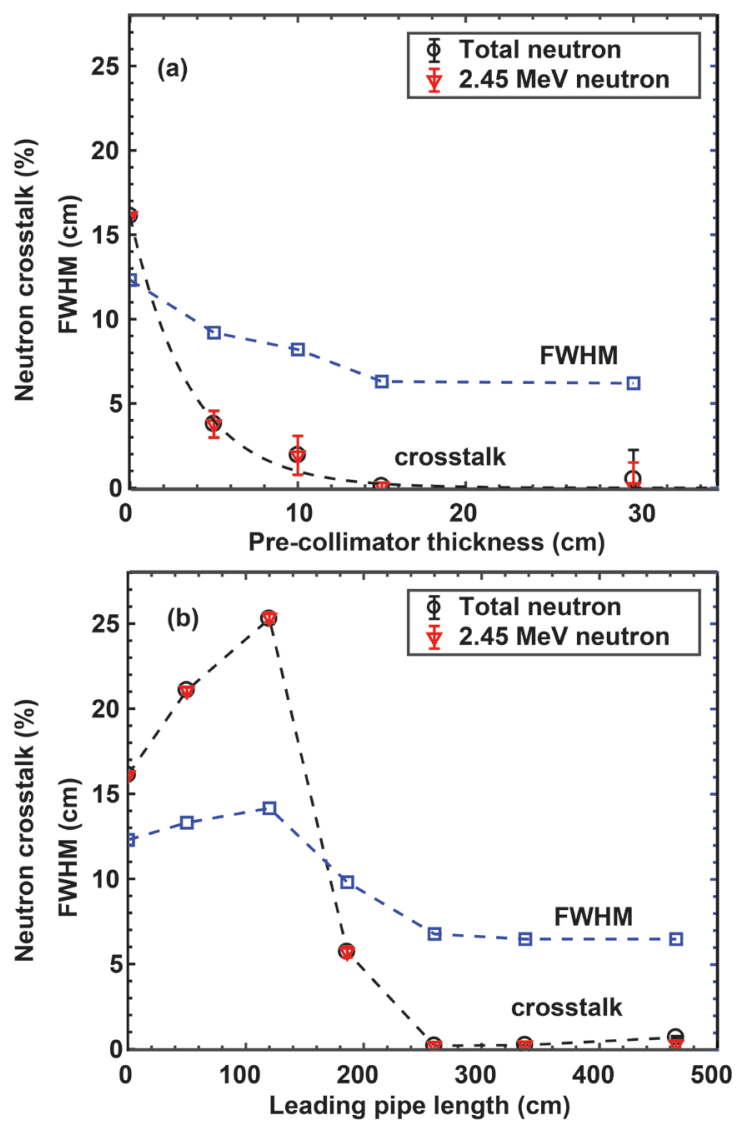

FIG. 10. Obtained results of neutron crosstalk and spatial resolution in FWHM for VNC3 with (a) different thickness of pre-collimator and (b) different length of leading pipe.

providing a better spatial resolution while the direct neutron is not affected.

For the leading pipe model (see Fig. 10(b)), the short length leading pipes (between $50 \mathrm{~cm}$ and $120 \mathrm{~cm}$ in this study) provide the higher neutron crosstalk than the current VNC3 status due to the reduction of about $25 \%$ of neutron flux in primary channel but insignificant reduction of neutron flux in secondary channel. A steep decrease of the neutron crosstalk is obtained when the length of leading pipe is more than $186 \mathrm{~cm}$. The length more than $260 \mathrm{~cm}$ of leading pipes provides less than $1 \%$ of the neutron crosstalk and spatial resolution of $\sim 6.5 \mathrm{~cm}$ in FWHM. The obtained results show that appropriate length of leading pipe allows smaller collimator diameter and longer collimated neutron beam to the detector, resulting in the reduction of the neutron crosstalk and providing the better spatial resolution. On account of the engineering and interfacing constraints of LHD torus and VNC3, the leading pipe with the length of $465.2 \mathrm{~cm}$ and the total weight of 0.07 tons is considered and will be developed for VNC3 in order to provide the higher performance on the reduction of neutron crosstalk and higher spatial resolution of neutron emission profile.

\section{SUMMARY}

Performance of VNC2 and VNC3 at LHD have been evaluated using the MCNP6 calculation in this work. New vertical neutron cameras at LHD show the high collimation performance characterized by high virgin neutron flux collimated to the detector. VNC2 provides a higher spatial resolution than $\mathrm{VNC} 3$, due to the additional $416 \mathrm{~cm}$ long stainless steel pipe along the collimator axis. The VNC2 and VNC3 show the capability to observe the poloidal structure of helically-trapped beam ions created by the P-NBs injection at different plasma cross-sections in the LHD deuterium experiment with the high temporal and spatial resolutions. In order to reduce the neutron crosstalk of $\mathrm{VNC}$, we are considering to install additional collimators, pre-collimator, and leading pipe. To achieve the $1 \%$ neutron crosstalk and design constraints, the leading pipe with 465.2 $\mathrm{cm}$ is suggested for installation on VNC3.

\section{DATA AVAILABILITY STATEMENT}

The data that support the findings of this study are available from the corresponding author upon reasonable request.

\section{ACKNOWLEDGMENTS}

This research was partly supported by NIFS Collaboration Research programs (KOAH037), and by the LHD project budget (ULHH003, ULHH034, and ULGG801). We are pleased to acknowledge the assistance in the MCNP6 calculations of S. Conroy of Culham Centre for Fusion Energy.

\section{REFERENCES}

${ }^{1}$ A. Fasoli, C. Gormenzano, H. L. Berk, B. Breizman, S. Briguglio, D. S. Darrow, N. Gorelenkov, W. W. Heidbrink, A. Jaun, S. V. Konovalov, R. Nazikian, J. M. Noterdaeme, S. Sharapov, K. Shinohara, D. Testa, K. Tobita, Y. Todo, G. Vlad and F. Zonca (2007). "Chapter 5: Physics of energetic ions," Nuclear Fusion 47, S264, https://doi.org/10.1088/0029-5515/47/6/s05

${ }^{2}$ A. L. Roquemore, R. C. Chouinard, M. Diesso, R. Palladino, J. D. Strachan, and G. D. Tait (1990). "TFTR multichannel neutron collimator," Review of Scientific Instruments 61, 3163, https://doi.org/10.1063/1.1141674

${ }^{3}$ A. L. Roquemore, M. Bitter, L. C. Johnson, and S. von Goeler (1997). "Recent expansion of the TFTR multichannel neutron collimator," Review of Scientific Instruments 68, 544, https://doi.org/10.1063/1.1147648

${ }^{4}$ J. M. Adams, O. N. Jarvis, G. J. Sadler, D. B. Syme, and N. Watkins (1993). "The JET neutron emission profile monitor," Nuclear Instruments and Methods in Physics Research Section A 329, 277, https://doi.org/10.1016/0168-9002(93)90947-g

${ }^{5}$ O. N. Jarvis, J. M. Adams, F. B. Marcus and G. J. Sadler (1997). "Neutron profile measurements in the Joint European Torus," Fusion Engineering and Design 34-35, 59-66,

https://doi.org/10.1016/S0920-3796(96)00672-2

${ }^{6}$ T. Craciunescu, G. Bonheure, V. Kiptily, A. Murari, S. Soare, I. Tiseanu, V. Zoita, and JET EFDA Contributors (2008). "The maximum likelihood reconstruction method for JET neutron tomography," Nuclear Instruments and Methods in Physics Research Section A 595, 623,

https://doi.org/10.1016/j.nima.2008.07.145 
${ }^{7}$ M. Ishikawa, T. Nishitani, A. Morioka, M. Takechi, K. Shinohara, M. Shimada, Y. Miura, M. Nagami and Yu. A. Kaschuck (2002). "First measurement of neutron emission profile on JT-60U using Stilbene neutron detector with neutron-gamma discrimination," Review of Scientific Instruments 73, 4237, https://doi.org/10.1063/1.1518145

${ }^{8}$ M. Ishikawa, T. Itoga, T. Okuji, M. Nakhostin, K. Shinohara, T. Hayashi, A. Sukegawa, M. Baba and T. Nishitani (2006). "Fast collimated neutron flux measurement using stilbene scintillator and flashy analog-to-digital converter in JT-60U," Review of Scientific Instruments 77, 10E706, https://doi.org/10.1063/1.2221927

${ }^{9}$ M. Ishikawa, M. Takechi, K. Shinohara, C. Z. Cheng, G. Matsunaga, Y. Kusama, A. Fukuyama, T. Nishitani, A. Morioka, M. Sasao, M. Baba and JT-60 team (2007). "Confinement degradation and transport of energetic ions due to Alfvén eigenmodes in JT-60U weak shear plasmas," Nuclear Fusion 47, 849-855, https://doi.org/10.1088/0029-5515/47/8/016

${ }^{10}$ F. B. Marcus, O. N. Jarvis, M. Loughlin, G. Sadler, P. Stott, J. M. Adams, D. S. Bond, N. P. Hawkes, N. Watkins, P. Batistoni, M. Rapisarda, T. Elevant, L. Johnson, L. de Kock, and C. Walker (1997). "A neutron camera for ITER (invited)," Review of Scientific Instruments 68, 514, https://doi.org/10.1063/1.1147619

${ }^{11}$ D. Marocco, B. Esposito and F. Moro (2012). "Neutron measurements in ITER using the Radial Neutron Camera," Journal of Instrumentation 7, C03033, https://doi.org/10.1088/1748-0221/7/03/c03033

${ }^{12}$ H. Matsushita, K. Ida, S. Okamura, M. Isobe, R. Akiyama, and Y. Yoshimura (2004). "Loss cone boundary measurement using diagnostic neutral beam and neutral particle analyzer in a compact helical system," Review of Scientific Instruments 75, 3607, https://doi.org/10.1063/1.1785263

${ }^{13}$ M. Osakabe, M. Isobe, S. Murakami, S. Kobayashi, K. Saito, R. Kumazawa, T. Mutoh, T. Ozaki, M. Nishiura, E. Veshchev, T. Seki, Y. Takeiri, O. Kaneko, K. Nagaoka, T. Tokuzawa, K. Ogawa, K. Toi, S. Yamamoto, M. Sasao, T. Watanabe and LHD Experiment Group (2010). "Fast-Ion Confinement Studies on LHD," Fusion Science and Technology 58, 131-140, https://doi.org/10.13182/FST10-A10800

${ }^{14}$ M. Isobe, M. Osakabe, T. Ozaki, M. Nishiura, P. V. Goncharov, E. Veshchev, K. Ogawa, K. Nagaoka, K. Saito, S. Murakami, T. Saida, M. Sasao, K. Toi and LHD Experiment Group (2010). "Fast-Particle Diagnostics on LHD," Fusion Science and Technology 58, 426-435, https://doi.org/10.13182/FST10-A10828

${ }^{15}$ T. Saida, M. Sasao, M. Isobe, A. V. Krasilnikov, R. Kumazawa, T. Mutoh, T. Watari, T. Seki, K. Saito, S. Murakami, K. Matsuoka and LHD Experimental Group (2004). "Study of ripple-trapped proton behaviour in LHD by two line-of-sight measurements of fast neutrals," Nuclear Fusion 44, 488-495, https://doi.org/10.1088/0029-5515/44/4/002

${ }^{16}$ M. Osakabe, Y. Takeiri, T. Morisaki et. al. (2017). "Current Status of Large Helical Device and its prospect for deuterium experiment," Fusion Science and Technology 72, 199-210,

https://doi.org/10.1080/15361055.2017.1335145

${ }^{17}$ M. Isobe, K. Ogawa, T. Nishitani, N. Pu, H. Kawase, R. Seki, H. Nuga, E. Takada, S. Murakami, Y. Suzuki, M. Yokoyama, M. Osakabe and LHD Experiment Group (2018). "Fusion neutron production with deuterium neutral beam injection and enhancement of energetic-particle physics study in the large helical device," Nuclear Fusion 58, 082004, https://doi.org/10.1088/1741-4326/aabcf4

${ }^{18}$ K. Ogawa, M. Isobe, T. Nishitani, S. Murakami, R. Seki, H. Nuga, S. Kamio, Y. Fujiwara, H. Yamaguchi, Y. Saito, S. Maeta, M. Osakabe and LHD Experiment Group (2019). "Energetic ion confinement studies using comprehensive neutron diagnostics in the Large Helical Device," Nuclear Fusion 59, 076017, https://doi.org/10.1088/1741-4326/ab14bc

${ }^{19}$ M. Isobe, K. Ogawa, T. Nishitani, H. Miyake, T. Kobuchi, N. Pu, H. Kawase, E. Takada, T. Tanaka, S. Li, S. Yoshihashi, A. Uritani, J. Jo, S. Murakami, M. Osakabe, and LHD Experiment Group (2018). "Neutron diagnostics in the Large Helical Device," IEEE Transactions on Plasma Science 46, 6, http://doi.org/10.1109/TPS.2018.2836987

${ }^{20} \mathrm{~K}$. Ogawa, M. Isobe, E. Takada, Y. Uchida, K. Ochiai, H. Tomita, A. Uritani, T. Kobuchi, and Y. Takeiri (2014). "Progress in development of the neutron profile monitor for the large helical device," Review of Scientific Instruments 85, 11E110, https://doi.org/10.1063/1.4890399

${ }^{21}$ K. Ogawa, M. Isobe, T. Nishitani, and T. Kobuchi (2018). "The large helical device vertical neutron camera operating in the $\mathrm{MHz}$ counting rate range," Review of Scientific Instruments 89, 113509,

https://doi.org/10.1063/1.5054818

${ }^{22}$ K. Ogawa, M. Isobe, H. Kawase, T. Nishitani, R. Seki, M. Osakabe and LHD Experiment Group (2018). "Observation of enhanced radial transport of energetic ion due to energetic particle mode destabilized by helicallytrapped energetic ion in the Large Helical Device," Nuclear Fusion 58, 044001, https://doi.org/10.1088/1741-4326/aaab18

${ }^{23}$ K. Ogawa, M. Isobe, H. Kawase, T. Nishitani, R. Seki, M. Osakabe and LHD Experiment Group (2018). "Effect of the helically-trapped energeticion-driven resistive interchange modes on energetic ion confinement in the Large Helical Device," Plasma Physics and Controlled Fusion 60, 044005, https://doi.org/10.1088/1361-6587/aaab1f

${ }^{24}$ S. Murakami, A. Wakasa, H. Maaßberg, C. D. Beidler, H. Yamada, K. Y. Watanabe and LHD Experimental Group (2002). "Neoclassical transport optimization of LHD," Nuclear Fusion 42, L19, https://doi.org/10.1088/0029-5515/42/11/101

${ }^{25}$ R. Seki, Y. Matsumoto, Y. Suzuki, K. Watanabe, K. Hamamatsu and M. Itagaki (2010). "Monte-Carlo study based on real coordinates for perpendicularly injected high-energy ions in the LHD high-beta plasma," Plasma and Fusion Research 5, 014, https://doi.org/10.1585/pfr.5.014

${ }^{26}$ See $\quad$ https://eljentechnology.com/images/products/data_sheets/EJ410.pdf for the specification of EJ-410.

${ }^{27}$ See

https://www.hamamatsu.com/resources/pdf/etd/High_energy_PMT_TPM Z0003E.pdf for the specification of H7195 PMT.

${ }^{28} \mathrm{See}$

https://s1.dtsheet.com/store/data/000749671.pdf?key=2f4cb749296cb6e8 $895 \mathrm{ac} 79 \mathrm{f} 7 \mathrm{a} 1 \mathrm{c} 378 \mathrm{a} \& \mathrm{r}=1$ for the specification of $\mathrm{C} 7319$ preamplifier unit.

${ }^{29} \mathrm{See}$ https://www.ni.com/pdf/manuals/371231d.pdf for the specification of fast digitizer acquisition system PXI6133.

${ }^{30}$ D. B. Pelowits (2013). "MCNP6 User's Manual," LA-CP-13-00634, Los Alamos National Laboratory. https://menp.lanl.gov/menp manual.shtml

${ }^{31}$ M. B. Chadwick, et al. (2011). "ENDF/B-VII.1 Nuclear data for science and technology: Cross sections, covariances, fission product yields and decay data," Nuclear Data Sheets 112, 2887-2996,

https://doi.org/10.1016/j.nds.2011.11.002

${ }^{32}$ T. Nishitani, K. Ogawa and M. Isobe (2017). "Monte Carlo simulation of the neutron measurement for the Large Helical Device deuterium experiments," Fusion Engineering and Design 123, 1020-1024,

https://doi.org/10.1016/j.fusengdes.2017.02.038

${ }^{33}$ H. Kawase, K. Ogawa, T. Nishitani, N. Pu, M. Isobe and LHD Experiment Group (2019). "Evaluation of spatial resolution of neutron profile monitor in LHD," IEEE Transactions on Plasma Science 47, 1, https://doi.org/10.1109/TPS.2018.2876170

${ }^{34}$ T. Nishitani, K. Ogawa, H. Kawase, N. Pu, T. Ozaki and M. Isobe (2019). "Monte Carlo calculation of the neutron and gamma-ray distributions inside the LHD experimental building and shielding design for diagnostics," Progress in Nuclear Science and Technology 6, 48-51, http://doi.org/10.15669/pnst.6.48

${ }^{35} \mathrm{~T}$. Nishitani, K. Ogawa, K. Nishimura and M. Isobe (2016). "Radiation field estimation for the diagnostic and control components by Monte Carlo neutronics calculations with LHD 3-dimensional modeling," Plasma and Fusion Research 11, 2405057, https://doi.org/10.1585/pfr.11.2405057

${ }^{36}$ S. Kamio, Y. Fujiwara, K. Ogawa, M. Isobe, R. Seki, H. Nuga, T. Nishitani, M. Osakabea, and the LHD Experiment Group (2019). "Development of NPA array using single crystal CVD diamond detectors," Journal of Instrumentation 14, C08002, https://doi.org/10.1088/1748-0221/14/08/c08002 